\title{
14 Years' experience of esophageal replacement surgeries
}

\author{
Muhammad Saleem ${ }^{1} \cdot$ Asif Iqbal $^{1}$ - Uzma Ather ${ }^{2} \cdot$ Naveed Haider $^{1} \cdot$ Nabila Talat $^{1} \cdot$ Imran Hashim $^{1}$. \\ Muhammad Bilal Mirza ${ }^{1} \cdot$ Jamal Butt $^{1} \cdot$ Hassan Mahmud ${ }^{1} \cdot$ Fatima Majeed $^{1}$
}

Accepted: 5 March 2020 / Published online: 31 March 2020

(c) Springer-Verlag GmbH Germany, part of Springer Nature 2020, corrected publication 2020

\begin{abstract}
Background Esophageal replacement is a challenge to the therapeutic skills of surgeons and a technically demanding operation in the pediatric age group. Various conduits and routes have been described in the literature, each with their specific advantages and disadvantages. We carried out this retrospective study to share our experience of esophageal replacement. Methodology This study was conducted at the department of pediatric surgery The Children's Hospital and The Institute of Child Health, Lahore. The records of patients treated for esophageal replacement were reviewed. The patients under followup were called for clinical evaluation and assessed of long terms complications if any.

Results A total of 93 patients with esophageal replacement were included in the study. Esophageal replacement was done with gastric transposition in 84 cases (90\%), colon interposition in 7 cases $(7.5 \%)$ including one case of redo colonic interposition, and jejunal interposition in 2 cases (2\%). Routes of esophageal replacement were trans-hiatal in 71 (76\%), retrosternal in $13(14 \%)$, and trans-hiatal with thoracotomy in $9(10 \%)$ patients. Postoperatively, all of the conduits maintained viability. Wound infection was seen in $10(11 \%)$, wound dehiscence in $5(5 \%)$, anastomotic leak in $9(10 \%)$, anastomotic stenosis in $12(13 \%)$, fistula formation in $4(4 \%)$, aortic injury $1(1 \%)$, dumping syndrome $8(9 \%)$, reflux $18(19 \%)$, dysphagia $15(16 \%)$ and death occurred in 12 patients (13\%).

Conclusion There are problems with esophageal replacement in developing countries. In this context, gastric conduit appeared as the best conduit for esophageal replacement, using the trans-hiatal route for replacement, in the authors' experience.
\end{abstract}

Keywords LMIC · Esophageal replacement · Gastric pull-up · Colonic interposition · Jejunal transposition · Corrosive strictures $\cdot$ Esophageal atresia $\cdot$ Trans hiatal route $\cdot$ Retrosternal route

\section{Introduction}

In children, indications for esophageal replacement include esophageal corrosive strictures not amenable to dilatations, long gap esophageal atresia, long-segment congenital esophageal stenosis (CES), esophageal malignancies and some rare esophageal disorders [1, 2]. The various conduits used for replacement are gastric pull-up, gastric tube formation, colonic interposition, and jejunal interposition. The option selected depends upon anatomic factors, previous surgery, the extent of corrosive injury to esophagus and stomach and surgical expertise of the surgeon [3]. Every conduit

Muhammad Saleem

msalimc@yahoo.com; msalimc63@gmail.com

1 The Children's Hospital and The Institute of Child Health, Lahore, Pakistan

2 Cresecent Medical college, Lahore, Pakistan and route of esophageal replacement has its own merits and demerits [1]. Additional procedures may be required in case of various short term and long term complications. Meticulous surgical technique and postoperative care are required for optimal outcome [4].

Herein, we share our 14-years experience of esophageal replacement, with various conduits especially with gastric pull-up, in terms of etiology, surgical details, complications encountered and their management, outcome, and follow-up.

\section{Methodology}

This retrospective descriptive case series was conducted at the department of Pediatric Surgery, The Children's Hospital and The Institute of The Child's Health Lahore from July 2005 to June 2019. Permission was taken from the Institutional Ethical Review Board. The charts of all patients treated for esophageal replacement were reviewed in depth. 
A self- structured Pro-forma was used for data collection. The data includes the demographic details (age, gender) presenting complaints, indications of esophageal replacement, investigations, operative procedure, complications, outcome, and follow-up. The patients were called for clinical evaluation during the data collection and assessed for any late complications. The collected data were analyzed using SPSS version 24 . The descriptive frequencies were analyzed for quantitative data and percentages were documented for qualitative data.

\section{Results}

A total of 93 patients with esophageal replacement were included. Males were $61(65.59 \%)$ and females $32(34.41 \%)$ with male to female ration of $1.9: 1$. Seven of these were referred from other provinces and Afghanistan. The mean age was 63.87 months \pm 50.16 with a range of one day to 180 months.

The majority of the patients were booked through outpatient clinics for esophageal replacement who were on our regular follow-up and declared non-dilatable in case of corrosive injury or with esophagostomy and gastrostomy for long gap esophageal atresia. The patients of congenital esophageal stenosis and esophageal tumor presented the complaints of dysphagia, weight loss, regurgitation, and repeated chest infections. Neonates were booked from nursery ICU for esophageal replacement. The etiology of esophageal replacement included caustic ingestion in 68 (73.11\%) patients, isolated long gap esophageal atresia in $13(13.97 \%)$, long gap esophageal atresia with tracheaesophageal fistula in $5(5.37 \%)$, congenital esophageal stenosis in $4(4.30 \%)$, esophageal tumor in $2(2.15 \%)$, and one patient with repeated failed surgeries for long segment cardiac achalasia.

These patients underwent various assessments such as nutritional status, blood labs, chest X-ray and contrast esophagogram, and esophagoscopy before surgery. In 44 (47.31\%) patients feeding jejunostomy and in six patients feeding gastrostomy was already done for feeding purpose (these were corrosive patients); whereas, in 15 (16.12\%) patients feeding gastrostomy and esophagostomy was done for long gap esophageal atresia. Twelve patients $(12.90 \%)$ with corrosive injury, who had relatively good health, required total parenteral nutrition through a central venous line for weight optimization for a short period before surgery. The remaining 13 (13.97\%) patients,(4 CES, 2 tumor, 6 corrosive, 1 Cardiac achalasia) were on oral nutrition as they were in relatively better health and was still able to take nutrition orally. They were directly subjected to replacement surgery. Feeding jejunostomy was preferred method for nutritional support in corrosive stricture patients if needed, as we wanted to spare the stomach for pull up. These are the patients who had weight less then 70th percentile for age and had esophageal strictures that were non-negotiable on dilatation and unable to take orally. Feeding gastrostomy was preferred in esophageal atresia patients, as jejunostomy was considered unsafe in the neonatal age group. All these patients were discussed with nutritionist and case-specific diet plan and response was monitored during fallow up visits.

After optimization, these patients underwent esophageal replacement. Three patients underwent primary gastric pullup. These are patients with isolated long gap esophageal atresia. The most common conduit was stomach as gastric pull-up based on right gastric and right gastro-epiploic vessels and next common conduit was colonic interposition, based on middle colic artery (right colon-isoperistaltic). The commonly used route was trans-hiatal route ( 80 patients) either isolated this route (71 patients) or combined with thoracotomy (9 patients) in difficult cases. Table 1 describes the details of conduits utilized and routes of replacement in our series. Our preferred conduit was gastric pull-up (84 patients). Next preference was colon (7 patients) if not available then we used jejunum in two patients. Additionally, in one patient pyloroplasty was done, whereas in 45 $(48.39 \%)$ patients of gastric pull-up, pyloromyotomy was done to avoid hold up in the chest. Moreover, we used a GIA linear cutter/stapler for gastroesophageal junction excision in all cases of gastric pull-up. Whenever the transhiatal route was used native esophagus was removed, however, where retrosternal route was used esophagus was left in situ (Fig. 1). The fundus was then anastomosed with the upper esophageal pouch. In one patient with jejunal interposition, the lower esophagus and stomach both were very scarred due to corrosive fibrosis; therefore, a roux-en-y loop of jejunum was pulled-up to the chest and anastomosed with the upper esophagus in the chest because the vascular arcade of jejunum posed difficulty in the procedure. In one case of colonic interposition using the retrosternal route, the lower end of colon had to be anastomosed with jejunum due to complete scarring of the stomach. In another patient with a corrosive long esophageal stricture along with gastric antral/ pyloric stricture (who developed complete re-stenosis after

Table 1 Conduit and route used for replacement

\begin{tabular}{lllllll}
\hline Conduits & & & Routes \\
\cline { 1 - 1 } Conduit & No. patients & \%age & & Route & No. patients & $\%$ age \\
\hline Stomach & 84 & 90.32 & & Trans-hiatal & 71 & 76.34 \\
Colon & 7 & 7.52 & & $\begin{array}{c}\text { Transhiatal } \\
\text { combined }\end{array}$ & 9 & 09.67 \\
& & & $\begin{array}{l}\text { with thora- } \\
\text { cotomy }\end{array}$ & \\
Jejunum & 2 & 2.15 & & Retrosternal & 13 & 13.98 \\
\hline
\end{tabular}




\section{GASTRO ESOPHAGEAL JUNCTION}
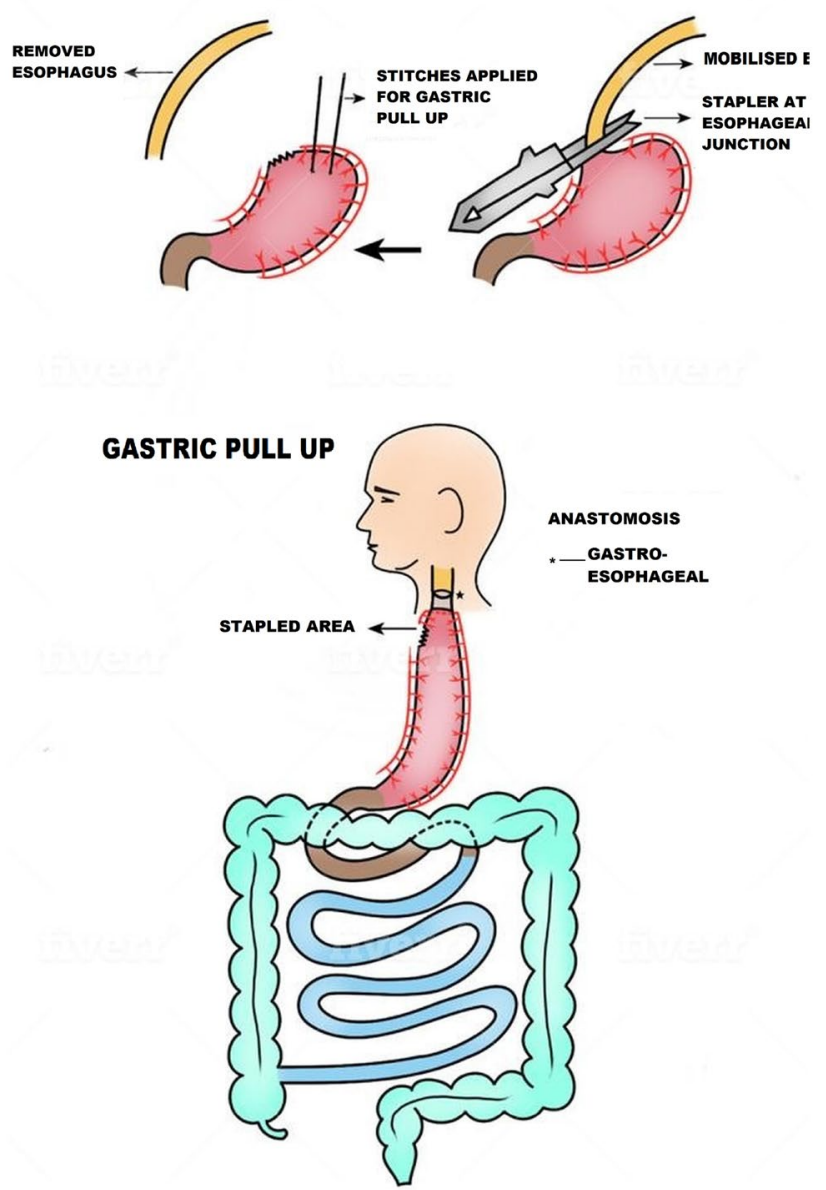

Fig. 1 Showing gastric pull-up technique (removal of esophagus from stomach with stapler and gastric pull up)

pyloroplasty), colonic interposition through the retrosternal route was performed with anterior wall of stomach along with gastroduodenostomy to bypass the pylorus (Fig. 2). In three patients with retrosternal route, the manubrium sterni was also removed per operatively due to compression on the conduit. This is based on the finding that two patients with dysphagia after esophageal replacement improved after resection of the manubrium sterni. Accordingly, in the following cases using the retrosternal route we made this standard that when the thoracic inlet is too tight that even two fingers can not be negotiated (subject to author's assessment) manubrial resection should be done. In nine cases, the chest had to be opened in patients with CES, tumor, cardiac achalasia and one for technical difficulty due to either fibrosis secondary to corrosive ingestion and one due to injury to the aorta. One patient was referred from another hospital with dehisced colonic interposition. This patient was operated by median sternotomy and re-anastomosis with both upper esophagus and colon was performed. In eight patients, anastomosis was performed in the chest (four CES and two tumors done using a partial gastric pull-up, and two jejujnal replacement for caustic stricture). In 85 patients, the anastomosis was performed in the neck.

Table 2 describes early and late per/postoperative complications in our series. Per operatively, we have encountered one aortic arch injury, which was dealt with help of cardiac surgeon after open thoracotomy. Postoperatively, various complications were encountered. Common early complications were pneumothorax in $10(10.75 \%)$ (3 on table and 7 in early postoperative period), anastomotic leak in $9(9.68 \%)$ [3 in chest (one with jejunal transposition, 2 with partial gastric pull-up) and 6 in neck], and wound infection in 10 $(10.75 \%)$ patients. The pneumothorax was dealt with tube thoracostomy. Anastomotic leaks (nine patients) were managed conservatively; out of those, seven healed ultimately. Wound infection was dealt with daily dressings and wound management. One patient who presented with anastomotic stricture needed median sternotomy and revision of anastomosis 5 years after the previous gastric pull-up through retrosternal route. Three more patients with anastomotic stricture with gastric pull up needed revision of anastomosis in neck, years after initial replacement surgery. One of these was operated 7 years after initial replacement, succumbed to death due to aspiration. Rest of patients with anastomotic strictures, were dealt with anastomotic dilatation with metallic/gum elastic bougies. In two patients, the manubrium was contributing to the postoperative dysphagia so manubrium sterni was removed afterward. One of patient with colonic transplant had signs of obstruction in the early postoperative period and on exploration revealed internal herniation in leftover defect of mesentery. We encountered one case of colonic dilatation post-operatively where we performed a re-do surgery. However, no case of gastric dilatation was seen in our series. So our four patients needed revision of anastomosis, one through median sternotomy. Dumping syndrome was observed in eight patients (8.6\%) of gastric pull-up and all of these patients had pyloromyotomy as additional procedure. In our experience, there was no difference of gastric content hold up with or without pyloromyotomy; it was associated with dumping syndrome in eight patients. Patients with reflux were managed medically.

In this series, 12 patients succumbed to death. One patient of isolated long gap esophageal with gastric pullup through trans-hiatal route could not be weaned off ventilator due to high intrathoracic pressure and ultimately acquired sepsis and died after 15 days. Two patients died due to mechanical ventilator failure, which remained undetected. Two patients with isolated long gap atresia having primary gastric pull died due to sepsis in the early postoperative period. Two patients (one with carcinoma of the lower esophagus and other one CES with partial gastric pull up) died in the early postoperative period due to a leak 


\section{COLONIC PULL UP WITH GASTRO-DUODENOSTOMY}

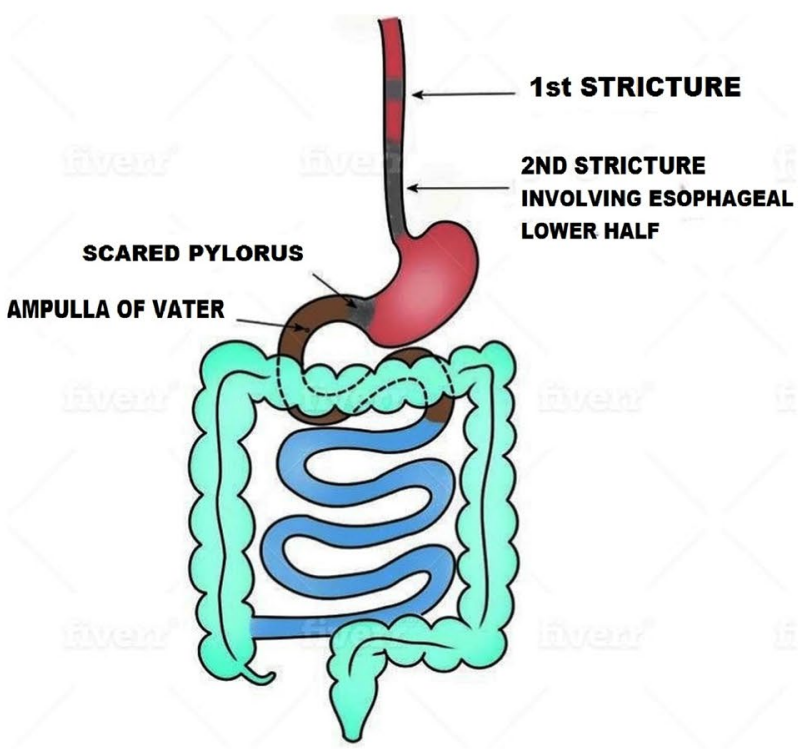

a Pathological Anatomy showing the disease involving esophagus and pylorus

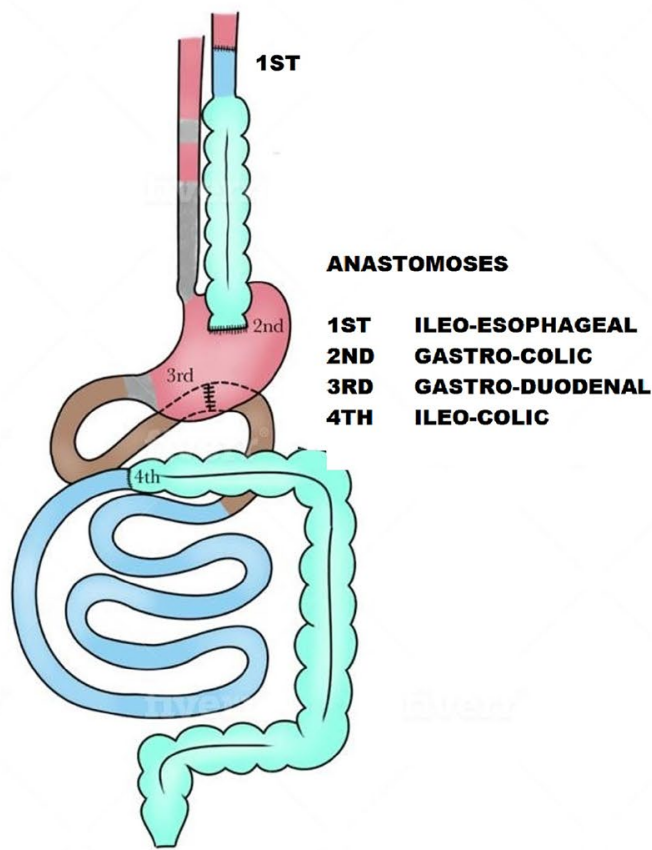

b Colonic pull up with gastroduodenostomy

Fig. 2 Diagrammatic presentation of anatomy following Colonic Pull-up and quadruple anastomosis

Table 2 Complications encountered in this case series

\begin{tabular}{|c|c|c|c|c|c|}
\hline \multicolumn{3}{|l|}{ Early complications } & \multicolumn{3}{|l|}{ Late complications } \\
\hline Complications & Number & Percentage & Complications & Number & Percentage \\
\hline Pneumothorax & 10 & 10.75 & Dysphagia & 15 & 16.13 \\
\hline Leak & 9 & 09.68 & Stricture/stenosis & 12 & 12.90 \\
\hline Wound infection & 10 & 10.75 & Reflux & 18 & 19.35 \\
\hline Wound dehiscence & 5 & 05.37 & Mortality & 12 & 12.90 \\
\hline Aortic injury & 1 & 01.01 & Fistula & 4 & 04.30 \\
\hline Internal herniation & 1 & 01.01 & Dumping Syndrome & 8 & 08.60 \\
\hline
\end{tabular}

in the chest. One with esophageal dilatation for corrosive stricture suffered from a leak and developed empyema. Despite decortication, esophagectomy and replacement carried out in the same setting, the patient succumbed to death postoperatively. One patient died due to aspiration after revision of anastomosis for anastomotic stricture. The remaining three patients died due to sepsis. After the initial follow-up of 2 years, the majority of patients were lost to follow-up. Currently, only 20 patients are on follow-up and doing fine. Out of these, 8 patients required esophageal dilatations (Table 3).

\section{Discussion}

Historically, in nineteenth-century first attempt for the reconstruction of esophagus was made using a subcutaneous skin tube. A host of conditions and diseases may require esophageal replacement such as long gap esophageal atresia, non-dilatable long esophageal corrosive strictures, more than 3-5 cm long congenital esophageal stenosis, and esophageal tumors [5]. In our series, the main indications of esophageal replacements were corrosive intake in $76.34 \%$ patients followed by esophageal 
Table 3 Route vs conduit

\begin{tabular}{lllll}
\hline Route & Stomach & Colon & Jejunum & Total \\
\hline Transhiatal & 70 & 1 & 0 & 71 \\
Transhiatal combined & 6 & 1 & 2 & 9 \\
$\quad$ with thoracotomy & & & & \\
Retrosternal & 8 & 5 & 0 & 13 \\
& 84 & 7 & 2 & 93 \\
\hline
\end{tabular}

atresia (19.35\%), congenital esophageal stenosis (4.30\%) and esophageal tumors $(2.15 \%)$. Garritano et al. performed a systemic review of the literature on pediatric esophageal replacement and found the most common reason for replacement was esophageal atresia followed by corrosive injury [6]. Also Soccorso and Dilshad et al. reported esophageal atresia and peptic disease as common indication for esophageal replacement $[1,7]$. These reports are contrary to our findings where majority of the patients belonged to corrosive ingestion and esophageal atresia was the second common etiology. This is due to lack of awareness among local community for safety measures regarding handling of corrosive material as compared to the developed countries where public awareness and industry collaborations have markedly reduced the incidence of corrosive injuries [1].

The commonly practiced conduits for esophageal replacement are colonic interposition, gastric pull-up, gastric tube interposition, jejunal interposition and jejunal free graft. The replacement can be performed through the esophageal hiatus, transthoracic, retrosternal, and occasionally through subcutaneous route. All the above mentioned conduit and routes used for replacement in literature have their own advantages and disadvantage. Choice is mainly depends upon patient's anatomy, available structures and surgical expertise. We preferred gastric-pull up ( $>90 \%$ of the patients) in our series, because of its technical advantages over other techniques in addition to our extensive experience for this procedure. It is because of the straight forward mobilization of stomach, with the blood supply based on the right gastric and right gastroepiploic vessels, and does not involve multiple anastomoses, thus the risk of anastomotic leakage is low. These factors have a direct impact on patient's morbidity and mortality. Although 6 patients developed anastomotic leakage in the neck, all were managed conservatively with free salivary drainage. We have a limited experience with colonic interposition (seven cases) and jejunal interposition (two cases) in patients with scarred stomach. In one patient we faced colonic dilatation and in cases of jejunal interposition, we encountered difficulty in bringing up the jejunum owing to its limited vascular arcade as endorsed by Giampiero and
Dakeshesh [1]. These were the other reasons that we preferred gastric pull-up procedure. According to Spitz et al. [8] and Delshad et al. [7], esophageal replacement with complete stomach is the ideal procedure because it has low complication rate, however, Delshad et al. and others have noted that colon interposition is still the commonest practiced method for esophageal replacement in the world literature [6, 7, 9-12]. Hirschl et al. [13] reported that a colon interposition is a more complex endeavor than a gastric transposition. Other studies conclude that gastric pullup is the procedure of choice for centers in Europe and the United States [14]. Similarly, in our series, we had gastric pull-up for the majority of our patients [6, 8, 14-18].

Trans-hiatal route is the most commonly used route for esophageal replacement, as after esophagectomy through the hiatus, this route is readily available for any pull-up [1]. We used trans-hiatal route without thoracotomy in $76.34 \%$ cases and combined with thoracotomy was done in $9.7 \%$ of cases. In our series, the retrosternal route was used in $14 \%$ of cases. This is similar to the approach described by others, including Gupta et al. [15-17].

Complications are divided into intraoperative, early and late. In one case we had aortic tear at the level of arch of aorta during surgery, which was managed by open thoracotomy with the help of our cardiac surgeon. Other intraoperative complication encountered were related to operative difficulty in esophagectomy owing to massive adhesion with the surrounding structures and bleeding, which were dealt with by opening the chest. The most common early postoperative complications in this series were pneumothorax in $10.75 \%$ of cases, leak in $9.68 \%$ of patients, wound infection and dehiscence in $16.12 \%$ of patients, and one patient had internal herniation. Pneumothorax was commonly seen with trans-hiatal route and identified either on table or after shifting to surgical ICU and managed with immediate chest intubation. In several patients, we deliberately passed chest tube fearing a pneumothorax especially in cases with difficult esophagectomy owing to adhesions. Almost same incidence of pneumothorax (10-14\%), was reported in the literature. [18-20] In our series second common early complication was anastomotic leak (9.68\%). Our results were comparable with Bradshaw et al. [19] who encountered anastomotic leak in $14 \%$ of patients. Awad et al. noted it in $20 \%$ of his patients [21]. Choudhury et al. [18] found much higher leak rate 14/19 after gastric pull up. According to a systemic review, anastomotic leak with gastric pull up was seen in $22.8 \%$ while with colonic transposition in $19.7 \%$ of cases [20].

The most common late complication encountered in our series was dysphagia (16.13\%). This has not been well documented; in his systemic review, Garritano et al. [6] reported that only in two among 14 studies was this 
complication discussed. Nakahara et al. [22] reported that $42.9 \%$ of his cases suffered from dysphagia. The current study showed anastomotic stenosis/stricture in $12.90 \%$ and reflex in $19.35 \%$. Our results of stenosis/stricture were comparable with a systemic review conducted by Liu et al. [20] who reported that early anastomosis stricture were $10.2 \%$ (13/127) with gastric replacement, $11.9 \%$ (40/335) with colonic interposition, and $17.8 \%(8 / 45)$ with jejunal interposition. Awad et al. [21] in a review of 22 studies reported that $22 \%$ of children developed anastomotic stricture after esophageal replacement with stomach in early follow up which was later increased to $70 \%$ of the cases on long-tern follow-up. Another important complication is reflux; our results for postoperative reflex were similar to Jain et al. [23] (10\%). Lee et al. [24] found a very high rate of reflex $(\geq 90 \%)$ after esophageal replacement, using gastric conduit. Gupta et al. [15] mentioned that after gastric pull up the incidence of reflux was $60 \%$ at 3 months, $50 \%$ at 6 months and $40 \%$ at 1 year post-procedure. In our series current dumping syndrome was seen in 8 patients (8.60\%). Dumping syndrome and delayed gastric emptying was also under reported in many studies, however, Jain et al. [23] evaluated 10 patients at 90.5 months of follow-up evidencing a mean gastric emptying was $39.1 \mathrm{~min}$.

Overall mortality associated with esophageal replacement is variable in different series depending upon available resources, disease severity and surgical expertize [6]. In our series, we had 12 mortalities (12.90\%), which were mainly due to postoperative complications such as failure to wean off from ventilator, pneumonia, sepsis, anastomotic leak, esophageal tumor and two mechanical ventilatory failures. Awad et al [18] in a systemic review of esophageal replacement with stomach found $4.8 \%$ mortality rate (27/558). In another systemic review, Garritano et al. [6] reported that the overall mortality rate varies between $2-4 \%$ in various studies. Our mortality rate was higher, likely due to disease severity, and compromised intensive care setting.

\section{Conclusion}

There are problems with esophageal replacement especially in developing countries, with low resources and suboptimal intensive care services. In our experience, the gastric conduit as a pull-up is the best conduit as esophageal replacement, which has the advantage of single anastomosis and trans-hiatal route is best shortest route for replacement. Esophageal replacement has morbidity as well as mortality and needs long-term follow-up in many patients for the management of various late complications. The surgeons should be well versed for using various conduits and routes as the patients may have variable extent of corrosive injury to esophagus and stomach and limitation due to previous surgery. The treatment plan must be individualized as seen in our series.

\section{References}

1. Soccorso G, Parikh DH (2016) Esophageal replacement in children: challenges and long-term outcomes. J Indian Assoc Pediatr Surg 21:98-105

2. Chirica M, Brette MD, Faron M, Munoz Bongrand N, Halimi B, Laborde $C$ et al (2015) Upper digestive tract reconstruction for caustic injuries. Ann Surg 261:894-901

3. Bakshi A, Sugarbaker DJ, Burt BM (2017) Alternative conduits for esophageal replacement. Ann Cardiothorac Surg 6(2):137-143

4. Arul GS, Parikh D (2008) Oesophageal replacement in children. Ann R Coll Surg Engl 90(1):7-12

5. Bagolan P, Iacobelli BD, De Angelis P, Di Abriola GF, Laviani R, Trucchi A, Orzalesi M, Dall'Oglio L (2004) Long gap esophageal atresia and esophageal replacement: moving toward a separation? J Pediatr Surg 39(7):1084-1090

6. Garritano S, Irino T, Scandavini CM, Tsekrekos A, Lundell L, Rouvelas I (2017) Long-term functional outcomes after replacement of the esophagus in pediatric patients: a systematic literature review. J Pediatr Surg 52(9):1398-1408

7. Delshad S, Farhood P, Nasiri SJ (2007) Esophageal replacement in children: presentation of 18 cases and results of their surgical procedure. MJIRI 21(3):139-144

8. Spitz L, Kiely EM, Pierro A (2004) Gastric transposition in children. A 21 years experience. J Pediatr Surg 39(3):276-281

9. AbouZeid AA, Zaki AM, Safoury HS (2016) Posterior cologastric anastomosis: an effective antireflux mechanism in colonic replacement of the esophagus. Ann Thorac Surg 101(1):266-273

10. Abdel-Latif M, El-Shafei EA, El-Asmar KM et al (2016) Simple antireflux technique for the cologastric anastomosis: complementary step in retrosternal colon interposition procedure. Dis Esophagus 29(8):1002-1006

11. Lima M, Destro F, Cantone $\mathrm{N}$ et al (2015) Long-term follow-up after esophageal replace- ment in children: 45-year single-center experience. J Pediatr Surg 50(9):1457-1461

12. Coopman S, Michaud L, Halna-Tamine M et al (2008) Long-term outcome of colon interposition after esophagectomy in children. J Pediatr Gastroenterol Nutr 47(4):458-462

13. Hirschl RB, Yardeni D, Oldham K et al (2002) Gastric transposition for esophageal replacement in children: experience with 41 consecutive cases with special emphasis on esophageal atresia. Ann Surg 236(4):531-541. https://doi.org/10.1097/01.SLA.00000 30752.45065.D1

14. Molinaro F, Angotti R, Bindi E, Pellegrino C, Casini L, Messina $M$ et al (2017) An European multicentric study of esophageal replacements: gastric pull-up, jejunal interposition, colonic interposition. Allied J Clin Pathol 1(1):9-12

15. Gupta DK, Sharma S, Arora MK, Agarwal G, Gupta M, Grover VP (2007) Esophageal replacement in the neonatal period in infants with esophageal atresia and tracheoesophageal fistula. J Pediatr Surg 42(9): 1471-1477

16. Maurer SV, de Buys RA, Reinberg O (2013) Comparison of transhiatal laparoscopy versus blind closed-chest cervicotomy and laparotomy for esophagectomy in children. J Pediatr Surg 48(4):887-892

17. Angotti R, Molinaro F, Noviello C, Cobellis G, Martino A, Del Rossi C, Bianchi A, Messina M (2016) Gastric transposition as a valid surgical option for esophageal replacement in pediatric 
patients: experience from three Italian medical centers. Gastroenterol Rep 5(1):47-51

18. Choudhury SR, Yadav PS, Khan NA, Shah S, Debnath PR, Kumar V, Chadha R (2016) Pediatric esophageal substitution by gastric pull-up and gastric tube. J Indian Assoc Pediatr Surg 21(3):110

19. Bradshaw CJ, Sloan K, Morandi A, Lakshminarayanan B, Cox SG, Millar AJ, Numanoglu A, Lakhoo K (2018) Outcomes of esophageal replacement: gastric pull-up and colonic interposition procedures. Euro J Pediatr Surg 28(01):022-29

20. Liu J, Yang Y, Zheng C, Dong R, Zheng S (2017) Surgical outcomes of different approaches to esophageal replacement in long-gap esophageal atresia: a systematic review. Medicine (Baltimore). 96(21):e6942. https://doi.org/10.1097/MD.0000000000 006942

21. Awad K, Jaffray B (2017) Oesophageal replacement with stomach: a personal series and review of published experience. J Paediatr Child Health 53(12):1159-1166
22. Nakahara Y, Aoyama K, Goto T, Iwamura Y, Takahashi Y, Asai $\mathrm{T}$ (2012) Modified Collis-Nissen procedure for long gap pure esophageal atresia. J Pediatr Surg 47(3):462-466

23. Jain V, Sharma S, Kumar R, Kabra SK, Bhatia V, Gupta DK (2012) Transposed intrathoracic stomach: functional evaluation. Afr J Paediatr Surg 9(3):210

24. Lee HQ, Hawley A, Doak J, Nightingale MG, Hutson JM (2014) Long-gap oesophageal atresia: comparison of delayed primary anastomosis and oesophageal replacement with gastric tube. J Pediatr Surg 49(12):1762-1766

Publisher's Note Springer Nature remains neutral with regard to jurisdictional claims in published maps and institutional affiliations. 